\title{
A interpretância da língua em relação às funções inter-humanas do discurso na aquisição da linguagem via aspecto vocal da enunciação
}

The interpretation of the language in relation to interhuman functions of discourse in language acquisition through vocal aspect of enunciation

Marlete Sandra DIEDRICH*

(Universidade de Passo Fundo)

RESUMO

O objetivo deste estudo é refletir sobre o aspecto vocal da enunciação na experiência da criança na linguagem e sua relação de interpretância com as funções inter-humanas do discurso, na busca de compreender qual o papel dos arranjos vocais na aquisição da linguagem. Analisamse fatos de linguagem característicos da linguagem de uma criança na faixa etária dos dois anos aos dois anos e sete meses, obtidos em situação naturalística. Adota-se uma perspectiva enunciativa aquisicional, com enfoque em determinados arranjos vocais constitutivos do discurso da criança, percebidos na emissão e na percepção dos elementos vocais que marcam a relação enunciativa. As análises mostram que, ao mobilizar os arranjos vocais especificos nas modalidades assertivas, interrogativas e imperativas da frase, a criança se move no simbólico da língua para agir sobre o outro, o que comprova a passagem de locutor a sujeito, uma vez que, a partir da apropriação das formas da língua, a criança mobiliza as relações de interpretância para constituir seu espaço de dizer.

Palavras-chave: aquisição da linguagem; interpretância da língua; funções inter-humanas do discurso; arranjos vocais.

*. Professora pesquisadora da área de Línguistica do Curso de Letras- Habilitação Língua Portuguesa, Língua Inglesa e Respectivas Literaturas e do Programa de Pós-Graduação em Letras da Universidade de Passo Fundo. 


\section{ABSTRACT}

The aim of this study is to reflect about the vocal aspect of the enunciation in child's language experience and its relation of interpretation with the inter-human functions of speech, in seeking to understand what is the vocal arrangements function in the history of children's language acquisition in relation to another of enunciation. It is analyzed the language features characteristic of a child language in the age group from two years to two years and seven months, obtained in a natural situation. It is assumed an enunciatively perspective of language acquisition, focusing certain constituent vocal arrangements of child speech, which are known in the issue and the perception of vocal elements that mark the enunciation relationship. The analysis showed that in mobilizing the specific vocal arrangements in the assertive, interrogative and imperative modalities of the phrase, the child moves in the symbolic of the language to act on the other, which proves the passage from speaker to subject. Since, from the appropriation of the forms of the language, it mobilizes the relations of interpretation to constitute its space of saying.

Key-words: language acquisition; language interpretation; inter-human functions of discourse; vocal arrangements.

\section{Introdução}

Com base em princípios advindos dos estudos de Émile Benveniste acerca da experiência humana na linguagem, entendemos a aquisição da linguagem pela criança como uma experiência de significação, por meio da qual se realiza a tríade homem, linguagem e cultura. A criança, nessa experiência, se apropria da língua do adulto e, por meio dessa apropriação, apreende o mundo dos homens. Assumimos uma abordagem enunciativa aquisicional ${ }^{1}$ da experiência da criança na linguagem, segundo a qual, a criança, ao assumir ou ao ser assumida como alguém que diz, que evoca sentidos, está se historicizando de forma singular, dada a maneira como assume a sua língua e se singulariza por ela. No entanto, traz, em suas enunciações, vestígios da língua-discurso, do outro, representante da cultura na qual ela está imersa desde antes de seu nascimento. Essa cultura é revelada nos diferentes empregos da língua, caracterizados por atualizações decorrentes, entre outros fatores, 
da realização vocal da língua em instâncias enunciativas, aspecto que colocamos em destaque neste artigo.

Sendo assim, com o objetivo de refletir sobre o aspecto vocal da enunciação na experiência da criança na linguagem e sua relação de interpretância com as funções inter-humanas do discurso, apresentamos, na sequência, princípios acerca da tríade homem, linguagem e cultura que sustentam nosso ponto de vista a partir da leitura que fazemos da concepção enunciativa de Benveniste; de posse desses princípios, circunscrevemos nossa discussão ao aspecto vocal da enunciação e à singularidade do ato enunciativo, bem como sua manifestação na experiência da criança na linguagem; para, por fim, apresentarmos o percurso metodológico de nossa pesquisa e a análise de dois recortes enunciativos representativos da linguagem da criança e reveladores da interpretância da língua em relação às funções inter-humanas do discurso.

\section{A tríade homem, linguagem e cultura na aquisição da linguagem}

A inserção da criança no mundo/na cultura se dá via discurso, ou seja, pela vivência de experiências marcadas por enunciações, sendo que entendemos enunciação conforme conceito apresentado por Benveniste (1970/1989: p. 82): “A enunciação é este colocar em funcionamento a língua por um ato individual de utilização". Para a criança constituir-se como sujeito do seu dizer e se historicizar na linguagem, ela ocupa lugares na enunciação por meio de operações da realização vocal da língua. Temos clareza de que as primeiras enunciações com as quais a criança tem contato, desde seu nascimento, são as enunciações faladas, consideradas por nós como um fenômeno específico de atualização da língua.

Nessa experiência, a criança, logo ao nascer, brinca com os sons de forma indistinta, pelo seu balbucio. Esse balbucio é abandonado à medida que o seu dizer passa a ser semantizado pelo outro. Acerca desse abandono, encontramos em Jakobson (1968) uma ampla explanação. Neste artigo e em nossa tese de doutorado ${ }^{2}$, a qual serviu de base para

2. Diedrich (2015). Disponível no repositório digital da Universidade Federal do Rio Grande do Sul em http://hdl.handle.net/10183/130026. 
esta reflexão, no entanto, vemos esse fenômeno como resultado da ação da cultura constituinte da língua, a qual se encarrega de filtrar os sons produzidos pela criança, de tal forma que ela passa a produzir apenas aqueles sons pertencentes à língua em uso, os quais servem à mobilização de sentidos autorizados na relação com o outro, que lhe "inculca" modos de agenciamento de formas, afinal, é um homem falando com outro homem que encontramos no mundo.

No ato efêmero da enunciação, segundo Benveniste (1970/1989: p. 83), o locutor faz uso de "procedimentos pelos quais as formas linguísticas da enunciação se diversificam e se engendram", trazendo à discussão o conceito de significância, o qual está intimamente relacionado à noção de "interpretância", uma vez que a língua categoriza e interpreta todos os demais sistemas, inclusive ela mesma. E é justamente por essa propriedade que a língua "constitui o que mantém juntos os homens, o fundamento de todas as relações que por seu turno fundamentam a sociedade" (Benveniste 1968/1989: p. 63).

A criança vive essa experiência no seio familiar desde cedo e, portanto, é capaz de mobilizar o aspecto vocal da língua em suas enunciações, mesmo quando ainda não enuncia formas linguísticas coincidentes às do adulto em suas regularidades fônicas. É no exercício da frase, marcada pela realização vocal da língua na enunciação, na relação de emissão e de percepção dos elementos vocais, que a criança se singulariza na sua experiência de linguagem em meio ao mundo de significações que a rodeia e que se constitui a partir de valores culturais.

Essa é a manifestação da cultura enquanto conjunto de valores. Segundo Silva e Stumpf (2012: p. 127), “Antes de querer significar o mundo ou correferir pelo discurso, o que é relevante para a criança, de início, parece ser essa relação prazerosa com os sons a que se entrega diante da sustentação do outro". Pensar nesse estatuto no ato de aquisição da linguagem nos leva a pensar na relação da criança com o adulto via discurso, uma vez que é do adulto que provém a institucionalização de valores linguístico-culturais.

A realização vocal da língua como um aspecto da enunciação é constitutiva do jogo simbólico construído no indivíduo desde o seu nascimento. Trata-se da emissão e da percepção dos elementos vocais 
carregando a linguagem, pois emissão e percepção não são fenômenos puramente fisiológicos; as unidades vocais emitidas e percebidas encontram seu destino na relação simbólica homem-linguagem-cultura, na qual as vocalizações da criança são revestidas de sentido na relação com o outro, possibilitando que as entendamos como manifestação da realização vocal da enunciação, uma vez que mobilizam sentidos únicos e particulares. Ocupamo-nos na sequência desse aspecto.

\section{O aspecto vocal da enunciação e a singularidade do ato enunciativo}

Benveniste (1970/1989: p. 82) faz referência à "realização vocal da língua" como um dos aspectos a partir dos quais pode ser estudado o grande processo da enunciação. Destacamos o uso, pelo linguista, do elemento sintático determinante "da língua" e não da "enunciação" ao se referir à "realização vocal". O autor afirma que, em relação à realização vocal da língua, encontramos no centro da questão a emissão de sons em atos individuais:

Os sons emitidos e percebidos, quer sejam estudados no quadro de um idioma particular ou nas suas manifestações gerais procedem sempre de atos individuais, que o linguista surpreende sempre que possível, numa produção nativa, no interior da fala (Benveniste 1970/1989: p. 82).

A partir dessa afirmação do autor, autorizamo-nos a pensar a realização vocal da língua como manifestação da singularidade do locutor no ato de apropriação da língua, uma vez que esse ato é particular e individual: "para o mesmo sujeito, os mesmos sons não são jamais reproduzidos exatamente, e que a noção de identidade não é senão aproximativa mesmo quando a experiência é repetida em detalhe" (Benveniste 1970/1989: p. 83). Essa condição revela especificidades acerca da relação do locutor com a língua relacionada à situação enunciativa, o que convoca à análise a relação locutor-língua, locutor-alocutário, locutor-enunciação, manifestadas nas vocalizações do locutor que se enuncia.

Essa discussão encontra eco na reflexão de Benveniste destacada em Vista d'olhos sobre o desenvolvimento da linguística, em que defende a linguagem como sistema simbólico em dois planos: 
de um lado é um fato físico: utiliza a mediação do aparelho vocal para produzir-se, do aparelho auditivo para ser percebida. De outro lado, é uma estrutura imaterial, comunicação de significados, substituindo os acontecimentos ou as experiências pela sua 'evocação'. (Benveniste 1963/2005: p. 30).

Vemos o autor destacar emissão e percepção, o que coloca no centro de sua discussão a intersubjetividade e a comunicação de significados evocada pela emissão vocal do locutor em relação ao outro e, principalmente, o fato de se tornar acessível a experiência de um falante a outro:

Aquele que fala faz renascer pelo seu discurso o acontecimento e a sua experiência do acontecimento. Aquele que o ouve aprende primeiro o discurso e através desse discurso, o acontecimento reproduzido. (Benveniste 1963/2005: p. 26).

Relacionamos essa passagem ao tratamento que o autor dá ao aspecto vocal da enunciação, ao afirmar que "os sons emitidos e percebidos [...] procedem sempre de atos individuais" (Benveniste 1970/1989: p. 82). Nas duas passagens, o linguista indica a possibilidade de entendermos a realização vocal da língua em relação ao fenômeno geral da enunciação, o que nos leva a destacar a intersubjetividade constitutiva desse ato. A realização vocal da língua, assim, envolve a emissão e a percepção dos sons da língua em atos individuais, o que revela especificidades decorrentes da diversidade das situações nas quais a enunciação é produzida.

Para darmos conta da definição do aspecto vocal da enunciação, entendemos ser necessário discutir os conceitos de emissão, percepção e situação, nela implicados, à luz da teoria benvenistiana. Tomemos, inicialmente, o conceito de emissão. Entendemos que no artigo em que é referido, O aparelho formal da enunciação, ele está relacionado ao fato de o locutor se apropriar dos sons da língua e enunciá-los à sua maneira, o que constitui a subjetividade da enunciação fônica, na qual o eu da enunciação se marca. Nessa realidade, a emissão dos sons da língua é também marcada por traços individuais decorrentes das situações nas quais a enunciação é produzida, o que entendemos como a singularidade do aspecto vocal da enunciação. Ao nos voltarmos para a singularidade da situação enunciativa, convocamos o conceito de per- 
cepção, o qual está em relação de complementaridade com o primeiro conceito. Relacionamos a ideia de percepção à presença do outro, do $t u$, na enunciação, uma vez que, desde o momento em que o locutor assim se declara e assume a língua, "ele implanta o outro diante de si" (Benveniste 1970/1989: p. 84, grifo do autor). Logo, se há uma singularidade na emissão dos sons da língua, decorrente da subjetividade com que o locutor se apropria dos elementos vocais, entendemos que há também singularidade na recepção desses sons, o que marca a relação de intersubjetividade entre $e u$ e $t u$. Por fim, voltamo-nos ao conceito de situação, referido por Benveniste como o responsável pelas diferenças de cada enunciação fônica do mesmo sujeito que se apropria dos sons da língua. Situação é a instância de discurso em que a enunciação acontece: o aqui-agora de cada enunciação, definido pela relação entre $e u$ e $t u$. Em resumo, ao propor a possibilidade de se estudar a realização vocal da língua como um aspecto da enunciação, Benveniste apresenta uma ideia que vem se opor ao que vinha se fazendo, na época, no universo dos estudos fonéticos e fonológicos, pois afirma que o aspecto referido de um modo geral não é visto em relação ao fenômeno geral da enunciação. Ou seja, os estudos em torno da realização vocal da língua mencionados por Benveniste, pautados na Fonética e na Fonologia, buscam, em geral, as regularidades dessa realização. O que propõe o linguista, entretanto, diz respeito às singularidades desse fenômeno, $\mathrm{o}$ qual, por essa razão, precisa ser visto como um dos aspectos do grande processo que é a enunciação.

Somente assim, "a realização vocal da língua" referida por Benveniste (1970/1989: p. 82) assume seu estatuto de aspecto em relação ao fenômeno geral da enunciação. Afirmamos isso motivados pela mesma metodologia usada pelo linguista no artigo $O$ aparelho formal da enunciação, ao considerar, segundo Flores (2008: p. 22), que a língua, como sistema que é, contém um aparelho de formas, cujo uso é dependente da enunciação. Flores (2013b: p. 168) afirma: “Ora, o locutor se apropria da língua, do aparelho formal da língua, para construir com ela um aparelho de enunciação". Segundo o autor (2013b: p. 168), "o dito aparelho formal de enunciação não é algo que esteja pronto aprioristicamente", pelo contrário, ele é construído a cada enunciação, a partir do aparelho de formas da língua. Seguindo esse raciocínio, entendemos que o que se realiza na enunciação fônica é a 


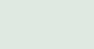

língua, mas completamente dependente do aqui-agora mobilizado na relação entre $e u$ e $t u$, tal qual constata Benveniste quando afirma:

Com o signo tem-se a realidade intrínseca da língua; com a frase liga-se às coisas fora da língua; e enquanto o signo tem por parte integrante o significado, que lhe é inerente, o sentido da frase implica referência à situação de discurso e à atitude do locutor (Benveniste 1966/1989: p. 230).

Por isso, entendemos que o "aspecto vocal da enunciação" é um dos aspectos propostos por Benveniste para o estudo da enunciação, o qual coloca em evidência a realização vocal da língua no discurso, marcada pela subjetividade do locutor que se apropria das unidades da língua e as enuncia à sua maneira na instância enunciativa, na relação intersubjetiva com o outro da enunciação. A instância enunciativa na qual se dá a realização vocal da língua é responsável pelas singularidades que marcam a emissão e a percepção dos elementos vocais na enunciação. Refletir sobre como isso se revela na experiência de aquisição da linguagem é nosso interesse na sequência.

\section{O aspecto vocal da enunciação na experiência de aquisição da linguagem}

Vemos a mobilização do aspecto vocal no dizer da criança atrelada à emissão e à percepção das vocalizações do outro. Mas não é um movimento em direção única. Salientamos que a polaridade emissãopercepção enunciativa pode ser vista pelo modo como as referências são atualizadas no fio do discurso nas relações enunciativas entre $e u$ e $t u$. Além disso, é a realização vocal da língua na enunciação do outro, em geral, da mãe, que convoca a criança ao sentido, semantizando suas vocalizações, mesmo quando a língua ainda não está explícita na manifestação da criança. A percepção empreendida pelo outro pode ser entendida como um fenômeno que conduz a criança à passagem de não falante a falante e de locutor a sujeito. É pela percepção do outro que ela abandona a condição de não falante e vive sua experiência de linguagem, o que significa mover-se no mundo simbólico à sua volta, por meio da realização vocal da língua, mobilizando arranjos vocais singulares. 
Na relação mútua de emissão e percepção, a criança, desde muito cedo, tem consciência do seu poder vocal, capaz de mobilizar os que se encontram em seu entorno. Essa consciência, certamente, resulta da mobilização do aspecto vocal da enunciação na relação com o outro, uma vez que a criança passa, aos poucos, a responder às emissões vocais daqueles que com ela convivem. Isso porque o homem constitui-se vivendo em sociedade e nela exercendo sua faculdade de simbolizar, por meio da linguagem, o que se efetiva a cada ato enunciativo, a cada vez que mobiliza aspectos vocais, construindo sentidos e unindo duas existências, tal qual afirmou Benveniste (1963/2005: p. 30): “torna a experiência interior de um sujeito acessível a outro numa expressão articulada e representativa, e não por meio de um sinal como um grito modulado; realiza-se numa determinada língua". Acessar o mundo à sua volta, portanto, é uma necessidade para a criança mover-se nesse mundo, e isso só acontece na relação simbólica vivida com e na língua, sempre em atos enunciativos, e vai constituir a experiência da criança na linguagem.

O papel de percepção das emissões vocais da criança pelo outro, por meio das relações simbólicas da língua, é imprescindível para a vivência dessa experiência, uma vez que da relação entre emissão e percepção dos arranjos vocais advém a possibilidade de significação. E é dessa relação também que advém a possibilidade de a criança se historicizar na língua-discurso, constituindo sua história de linguagem, uma vez que, em suas enunciações, ela se apropria dos elementos vocais da língua-discurso à sua maneira, imprimindo-lhes um caráter particular. Acerca disso, apoiamo-nos no dizer de Silva (2009: p. 247): "a criança, pela língua-discurso, constrói uma semântica particular, produzindo estruturas no uso, que se convertem em formas da língua na relação enunciativa constituída por $e u$ e por $t u$ ". Defendemos a ideia, portanto, de que os arranjos do aspecto vocal da enunciação fazem parte da semântica particular característica da linguagem da criança, a qual permite a relação entre o semiótico e o semântico a cada enunciação. A criança, assim, nas relações enunciativas decorrentes da emissão e da percepção dos elementos vocais da língua, inscreve-se na línguadiscurso, imprimindo à língua um caráter particular, o que revela, nos arranjos vocais da frase, uma relação direta da criança com a língua, com o outro, com a instância enunciativa. 
Vemos, nessas implicações, que a emissão e a percepção dos sons da língua em relação na enunciação possibilitam a criança historicizarse na língua-discurso, para fundamentar sua subjetividade na linguagem, ao se apropriar dos aparelhos de formas e de funções.

Nesse trabalho de construção simbólica, lembramos Flores (2013a). Ao abordar a problemática do sujeito da enunciação a partir do conceito de sintaxe da enunciação, o autor afirma: "Afunilar o sentido, ou seja, enunciar é, vale repetir, em última instância, uma apropriação imaginária marcada no simbólico por operações singulares que integram a syntaxe d'énonciation." (FLORES 2013a: p. 119, grifo do autor). Apesar de o autor não focalizar, nesse trabalho, o aspecto vocal da enunciação, vemos na referência a "operações singulares que integram a syntaxe d'énonciation" a possibilidade de relacionarmos o afunilamento de sentido que representa toda enunciação aos arranjos que integram o aspecto vocal da enunciação. Por meio da relação singular entre forma e sentido, os arranjos vocais que caracterizam as línguas em geral se particularizam no discurso por um ato do locutor que deles se apropria e se torna sujeito do seu dizer. É esse sujeito que, por meio de arranjos vocais, mobiliza a língua e impõe um ritmo ao dizer que o singulariza. A singularidade enunciativa, então, nos limites de nossa pesquisa, se faz conhecer via aspecto vocal, por meio de arranjos vocais específicos mobilizados pelo locutor. Isso porque cada criança que nasce e vive no mundo dos adultos reproduz ${ }^{3}$ sua experiência a cada ato enunciativo. Sendo assim, a criança entra no mundo da linguagem não via sistema de signos, mas via discurso, o que acontece, precipuamente, por meio da realização vocal, constituindo, assim, sua história.

Com Benveniste, vimos que, antes de tudo, a linguagem significa e que, para tanto, ela se realiza por meio de signos vocais que se organizam em palavras dotadas de sentido. Com essa proposição, o linguista apresenta uma outra maneira de se verem os fatos da língua, um outro domínio, a língua como semântica, resultante de "uma atividade do locutor que coloca a língua em ação" (Benveniste 1966/1989: p. 230). O sentido, na acepção semântica, se realiza formalmente na língua pelo

3. Destacamos, na perspectiva benvenistiana, , a importância do uso do prefixo "re" em "reproduz", uma vez que ele aponta para o fato de que, embora as formas linguísticas sejam as mesmas, elas se revestem, a cada enunciação, de características renovadas, próprias de cada ato enunciativo, conforme raciocínio de Dessons (2006). 
agenciamento de palavras, pela relação que elas exercem umas sobre as outras, diferentemente da acepção semiótica. Com o semântico, o linguista reconhece a entrada no modo de significância engendrado pelo discurso.

Os arranjos vocais mobilizados pela criança em suas enunciações, ao longo da sua experiência de linguagem, revelam operações que afetam as formas da língua e cumprem a função de integralizar essas formas no discurso, na totalidade da frase. Flores e Surreaux (2012: p. 86) veem nessa função determinadas relações às quais chamam de "ligação gramático-vocal-enunciativa", já que as compreendem como decorrrentes da concatenação entre os elementos segmentáveis da frase, o que coloca em evidência a transversalidade enunciativa sobre a qual se apoia o sentido no discurso. Os arranjos vocais do aspecto vocal da enunciação, em relação na emissão e na percepção, são, portanto, integralizadores de formas para comunicar e evocar sentidos nas enunciações que constituem a experiência da criança na linguagem.

Essa experiência é revelada na relação da criança com a línguadiscurso, na realização de propósitos significantes sobre a significância, conceito a ser focalizado a seguir em relação às funções inter-humanas do discurso.

\section{Propósito significante sobre a significância: a interpretância da língua em relação às funções inter-humanas do discurso}

Benveniste, ao discutir as relações entre língua e sociedade, afirma que "a língua interpreta a sociedade. A sociedade torna-se significante na e pela língua, a sociedade é o interpretado por excelência" (Benveniste 1968/1989: p. 98). A partir dessa ideia, entendemos que toda a organização da vida em sociedade, para ser compreendida, precisa do seu interpretante, que é a língua. Assim, o "semantismo social" está relacionado aos valores culturais impressos na realização vocal da língua na enunciação. Ao falar, portanto, o homem não apenas mobiliza formas e sentidos particulares explicitados na língua da qual se apropria, ele vai além, relaciona-se, pela mobilização de arranjos vocais, com os valores sociais, capazes de revelar muito acerca da sua 
história construída no seio de uma sociedade e da experiência por ele vivida no mundo que o cerca.

Usamos a expressão "propósitos significantes sobre a significância", conceito apresentado por Benveniste (1969/1989: p. 66) acerca do privilégio da língua de comportar simultaneamente a significância dos signos e a significância da enunciação. Dessa condição é que, segundo o autor, provém o poder da língua de criar um segundo nível de enunciação, "em que se torna possível sustentar propósitos significantes sobre a significância" (Benveniste 1969/1989: p. 66). A experiência da criança na linguagem, portanto, é sempre revelada por meio dos propósitos significantes sobre a significância, os quais se realizam na relação de interpretância da língua em relação aos demais sistemas e em relação a ela mesma, concretizada na tríade homem-linguagem-cultura e na qual o aspecto vocal da enunciação assume papel fundamental. A criança, ao mobilizar arranjos vocais na constituição do discurso, realiza propósitos significantes que procuram dar conta da realidade significante que não apenas a cerca, mas da qual ela faz parte, e os quais se sustentam em outras relações de significância instauradas a cada enunciação. Ao vivenciar essa relação, acreditamos que a criança se historiciza na linguagem, por meio da mobilização de arranjos vocais particulares, capazes de colocá-la em relação ao outro da enunciação.

Vemos no propósito significante que envolve a interprtância da língua em relação às funções inter-humanas do discurso a condição primeira para a aquisição da linguagem: "É um homem falando com outro homem que encontramos no mundo." (Benveniste 1958/2005: p. 285). E, nessa relação intersubjetiva, "O enunciador se serve da língua para influenciar de algum modo o comportamento do alocutário.” (Benveniste 1970/1989 : p. 86). Desde muito cedo, a criança vive situações enunciativas nas quais o outro, por meio de arranjos vocais mobilizadores de entonações específicas, sintagmatiza asserções, interrogações e intimações.

Focalizemos, na sequência, cada uma das funções sintáticas abordadas por Benveniste. A primeira delas, a interrogação, é apresentada pelo linguista como uma enunciação que suscita explicitamente uma resposta, o que o leva a entendê-la como "um processo linguístico que é ao mesmo tempo um processo de comportamento com dupla 
entrada" (Benveniste 1970/1989: p. 86) e justamente por isso capaz de unir duas existências a partir da relação emissão - percepção imbricada na enunciação. A interrogação, para Benveniste, está amparada nas formas lexicais e sintáticas que a compõem, nas partículas, nos pronomes e em muitos outros elementos que o autor deixa implícitos em sua enumeração. Para nós, no entanto, ganha relevância a referência à entonação, entendida em nosso trabalho como manifestação do aspecto vocal da enunciação e mobilizadora de sentidos particulares na instância enunciativa.

No que diz respeito à intimação, Benveniste (1970/1989:p. 86) a vê como uma enunciação que se constitui por meio de ordens, apelos, marcados por termos e formas que "implicam uma relação viva e imediata do enunciador ao outro". Apesar de o autor não referir manifestações específicas da realização vocal, sentimo-nos autorizados a entendê-las como parte da "relação viva e imediata do enunciador ao outro", sendo capaz, inclusive, de, por meio de tons ascendentes e alongamentos vocálicos, por exemplo, categorizar graus de intimação em cada instância enunciativa. Assim como a interrogação, a intimação convoca à discussão os conceitos de emissão e percepção que caracterizam a "relação viva e imediata do enunciador ao outro". Entendemos que os adjetivos "viva" e "imediata", usados por Benveniste como determinantes do substantivo "relação", colocam em relevo a enunciação como ato, o qual supõe o diálogo, pois desde que o locutor assim se declara e assume a língua, "ele implanta o outro diante de si" (Benveniste 1970/1989, p. 84). Essa relação entre $e u$ e $t u$, portanto, é viva e imediata, pois não há locutor sem o outro da enunciação; não há emissão sem percepção; e a intimação só se efetiva de fato na emergência da instância enunciativa.

A asserção, por sua vez, é vista como uma enunciação que visa a comunicar uma certeza, a qual também se apoia em formas linguísticas específicas, reveladas em seu rodeio sintático e em sua entonação, segundo o autor. Percebemos, mais uma vez, a referência à entonação como elemento presente no aparelho de funções sintáticas. Benveniste refere as formas "sim" e "não" como instrumentos específicos dessa função sintática, mas nos leva a entender que o emprego dessas formas é completamente dependente da instância enunciativa, o que nos permite entender o aspecto vocal da enunciação como uma operação que afeta 
tais formas linguísticas, mobilizando, a cada ato enunciativo, sentidos específicos na relação entre $e u$ e $t u$, no aqui-agora da enunciação.

Têm-se nessas modalidades da frase as atitudes fundamentais "do homem falando e agindo pelo discurso sobre seu interlocutor" (Benveniste 1964/2005: p. 139), o que entendemos como decorrência da relação intersubjetiva que leva a criança a vivenciar a passagem de locutor a sujeito. Essa relação é marcada, inicialmente, pela ação do outro, o qual convoca a criança ao dizer por meio da mobilização de diferentes procedimentos, em especial, pelo aspecto vocal da enunciação, revelado no discurso por meio dos arranjos vocais que constituem o aparelho de funções sintáticas. Na vivência da reversibilidade enunciativa, condição da enunciação, já que tu pode ocupar o lugar do $e u$ e vice-versa, a criança, ao longo de sua experiência na linguagem, apropria-se do aparelho de funções sintáticas e passa a ocupar, por meio da mobilização desse aparelho, o lugar de sujeito da enunciação. Há, nessa apropriação, o engendramento de determinadas formas e arranjos vocais específicos que colocam a criança em relação com as funções inter-humanas do discurso. Isso é possível em função de o lugar ocupado pela criança na estrutura enunciativa, conforme atestou Silva (2009: p. 233), ser primeiramente atribuído pelo outro, a cada vez que o outro lhe dirige a palavra. Ocorre, assim, o movimento, já abordado por Silva (2009), da passagem, pela criança, da condição de ser convocada à condição de convocar o outro.

Sendo assim, na sequência, explicitamos o percurso metodológico que dirigiu nosso estudo e ilustramos a análise realizada com a discussão de fatos de linguagem que marcam dois recortes enunciativos escolhidos do corpus da pesquisa para os propósitos deste artigo.

\section{Percurso metodológico e discussão dos fatos de linguagem}

Uma pesquisa na perspectiva enunciativa aquisicional trabalha com unidades de distintos níveis linguísticos que emergem na enunciação, o que impossibilita pensar, para fins de estudo, em escolha de formas e estruturas a priori. É justamente a interrogação dos fatos de linguagem que dirão ao analista que formas se revelam importantes em sua inves- 
tigação. Por isso, acompanhamos a criança em situações informais dos dois anos aos dois anos e sete meses de idade, buscando situações de diálogo, nas quais a criança interage com adultos ou com outra criança, como mostram os recortes analisados. É importante destacar que o aspecto vocal da enunciação realiza-se segundo o princípio da transversalidade enunciativa e afeta, como um constituinte integralizador da frase, as unidades apropriadas dos distintos níveis e constituintes da frase, na comunicação intersubjetiva e na evocação de sentidos na relação de emissão e percepção. Por essa razão, o diálogo constitui realidade importante em nossa pesquisa: "forma sonora que atinge um ouvinte e suscita uma outra enunciação de retorno". O diálogo, portanto, caracteriza os dados de análise. Além disso, o aspecto vocal da enunciação é responsável pela mobilização de sentidos particulares na busca empreendida pela criança de uma "certa relação com o mundo" a cada emprego de língua. Sendo assim, na análise, considera-se a situação enunciativa na qual os discursos emergem.

Ressaltamos que não se trata de períodos cronológicos diferentes na história de enunciações da criança, uma vez que, num mesmo recorte enunciativo, percebemos a criança assumir o seu lugar de sujeito na enunciação a partir da convocação do outro e também convocar o outro a enunciar, relações que se revelam por meio de arranjos vocais ilustrados nos recortes enunciativos a seguir analisados ${ }^{4}$.

4. Os recortes enunciativos analisados fazem parte do corpus de pesquisa de nossa tese de Doutoramento intitulada Aquisição da linguagem: o aspecto vocal da enunciação na experiência da criança na linguagem, disponível em http://hdl.handle.net/10183/130026. Para a transcrição, obedeceu-se às seguintes normas: letras maiúsculas marcam tons ascendentes; reticências marcam pausas; as repetições de vogais marcam alongamentos vocálicos; barras marcam interrupções. A linha nomeada de "comentário" apresenta descrições contextuais, enquanto a linha "corpo" diz respeito aos gestos constitutivos do dizer da criança, cuja simultaneidade vem marcada pela sequência de dois pontos (::.::). 


\section{Recorte Enunciativo 1: Tirar as meias}

Participantes: Dália, pai, mãe e tio Data da coleta: $30 / 06 / 2012$

Idade da criança: $2 ; 1 ; 6$

Situação: Dália senta no sofá ao lado do pai e do tio, sob o olhar da mãe, e quer tirar as meias dos pés, sob protesto dos pais.

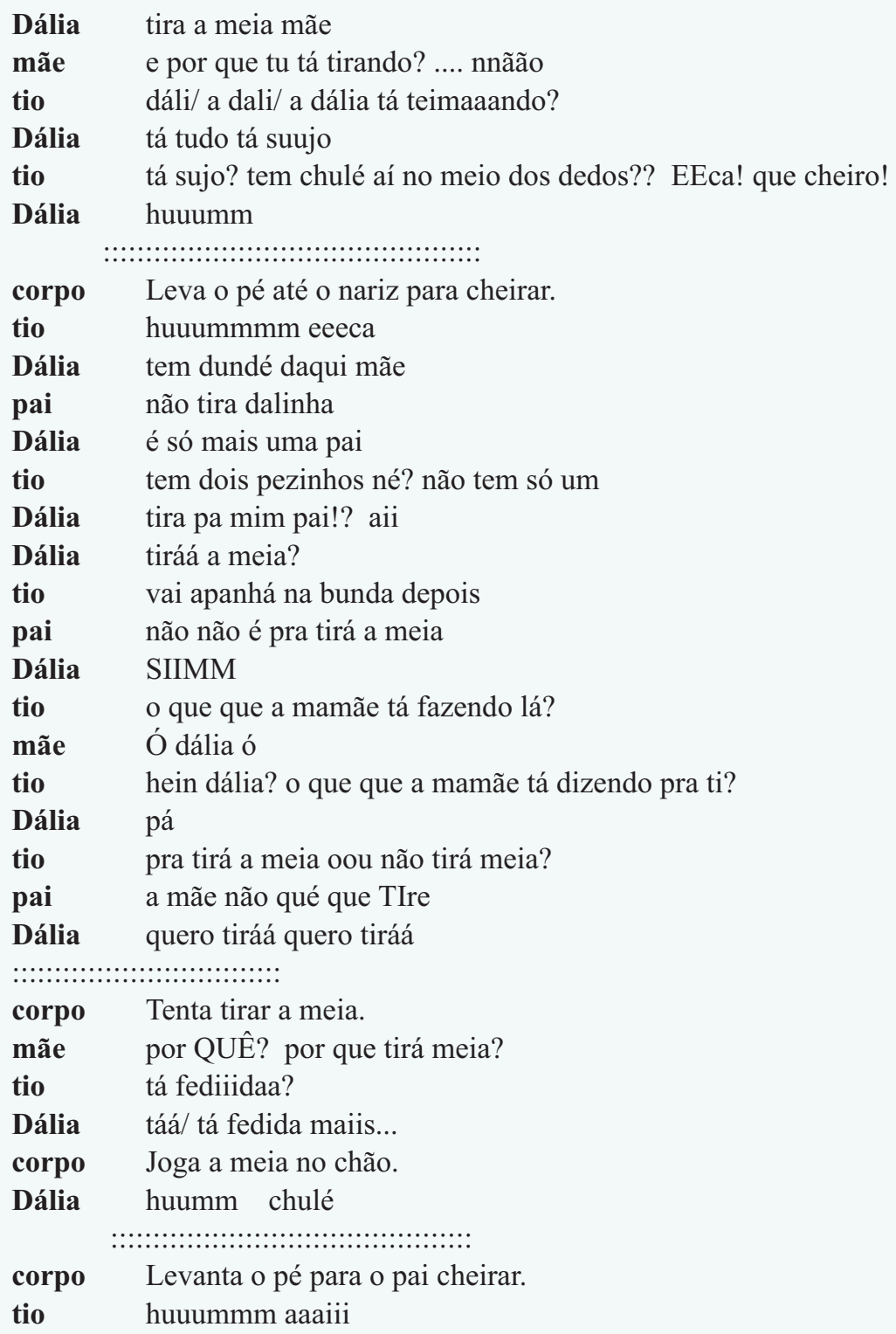




\section{Recorte Enunciativo 2: Já chega}

Participantes: Dália, Ber e Mar

Data da coleta: $27 / 12 / 2012$

Idade da criança: $2 ; 7 ; 3$

Situação: Dália e Ber disputam o domínio sobre um teclado de brinquedo enquanto Mar acompanha a brincadeira.

Dália tu cant/canta um poquinho e depois (...) dexa’u dexa’u/ ber já

$$
\text { CHEGA }
$$

corpo

Dália

não liga

Empurra Ber.

comentário Dália faz ruído com a boca como um chiado.

Ber eu não vô ligá dália

Dália tá ... não vai ligá... NÃO liga. não canta. não liga

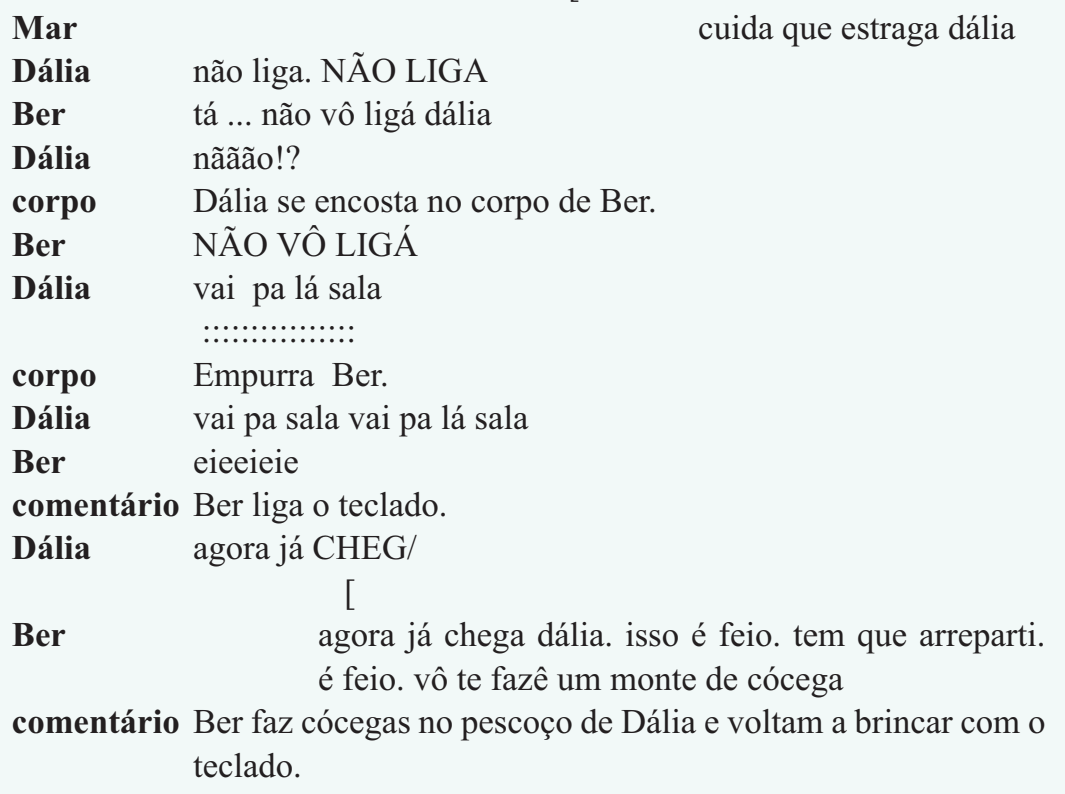

Vemos na relação intersubjetiva que marca as enunciações apresentadas nos recortes o outro convocar a criança a assumir o seu lugar de sujeito da enunciação, uma vez que observamos o outro, por meio de intimações e interrogações, relacionar-se com a criança, convocando-a (Silva 2009) a ocupar o seu lugar de eu na estrutura enunciativa. A reversibilidade enunciativa garante à criança esse lugar, assumido por ela 
sempre que se apropria do aparelho de formas e de funções da língua. Neste caso, entendemos que isso acontece principalmente por meio dos arranjos vocais revelados nos dois recortes, os quais possibilitam à criança, por meio das funções sintáticas mobilizadas, vivenciar, na linguagem, "uma relação viva e imediata" (Benveniste 1970/1989: p. 86) com o outro no tempo em que se realiza a enunciação.

Essa relação viva e imediata com o outro no tempo da enunciação coloca em destaque a noção de referência, uma vez que há uma diversidade de arranjos vocais em função da particularidade do momento específico em que a enunciação ocorre e da especificidade da relação discursiva que se estabelece, o que permite dizer que a especificidade de tais arranjos mobilizados no discurso é dependente da especificidade da referência, fazendo com que "cada instância do discurso seja um centro de referência interno" (Benveniste, 1970/1989: p. 84).

No recorte 1, observamos a mobilização de arranjos vocais no cumprimento das funções de intimação, de asserção e de interrogação. O alongamento vocálico marca a asserção. No momento em que é convocada pelo pai a responder a um questionamento sobre por que está tirando a meia, a criança mobiliza esse arranjo vocal para constituir sua resposta assertiva "tá tudo tá suujo", assim como faz em "quero tiráá quero tiráá" e em "SIIMM", enunciado que se opõe ao que o pai havia dito anteriormente. Essa oposição é percebida, principalmente, pelo alongamento vocálico e pelo tom ascendente que marca a enunciação da partícula assertiva. Nessa situação, há um misto de entonação interrogativa e exclamativa, mobilizadas muito mais como apelo do que como pergunta: "tira pa mim pai!? aii". Diferentemente do que ocorre em “tiráá a meia?", em que percebemos uma pergunta mais explícita em que o arranjo vocal denuncia uma entonação mais interrogativa sem a presença da entonação exclamativa.

No recorte 2, na vivência do conflito com o amigo em torno da disputa pelo teclado eletrônico, a criança emite ordens marcadas principalmente pelos tons ascendentes: "NÃO LIGA", "NÃO canta". Esse tom é abandonado quando o outro afirma que não vai ligar o brinquedo : "tá ... não vô ligá dália" e o que entra no jogo enunciativo são arranjos vocais caracterizados por entonações exclamativas e interrogativas que mostram a criança apreendendo o discurso do outro 
como forma de confirmar o que o outro diz: "nããão!?”. Esse recorte enunciativo ilustra muito bem o quanto a emissão vocal da criança está na dependência da percepção que ela tem dos arranjos vocais do outro. Afirmamos isso porque percebemos que o outro, neste caso, a criança mais velha, busca sempre apaziguar o conflito por meio da sua enunciação. No entanto, suas atitudes mostram o contrário, ele continua realizando a ação de brincar com o teclado, embora, em seu discurso, afirma que não mais brincará. Essa situação constitui a enunciação dos arranjos vocais mobilizados pela criança na relação de interpretância do evento vivido. A mobilização de sentidos particulares dependentes da emissão e da percepção dos arranjos vocais na relação criançaoutro é visível no segmento em que Dália novamente mobiliza tons ascendentes para impor uma ordem ao outro. O outro, na percepção do sentido mobilizado por esse arranjo, imprime ao seu enunciado um caráter apaziguador, retomando o enunciado de Dália, mas com outra entonação, o que mobiliza nova referência e novos sentidos na instância de discurso:

"Dália agora já CHEG/

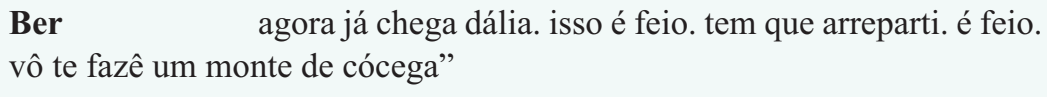

Percebemos que, sem a entonação ascendente, com marcações bem pausadas, o enunciado de Ber assume um novo sentido, que acaba se opondo à ideia de conflito instaurada por Dália em seu discurso, o que nos leva a afirmar que, de fato, os arranjos vocais, constitutivos dos atos de emissão e de percepção, afetam o sentido mobilizado na particularidade do discurso.

Merece destaque também, entre esses arranjos, a mobilização dos gestos constitutivos do dizer da criança. Nos dois recortes, podemos perceber, em especial, pelos aspectos descritivos que são revelados nas trilhas "comentário" e "corpo", que a criança também mobiliza os gestos como meio para atingir o outro no seu dizer, como uma forma de intensificar, asseverar, reafirmar o que explicita em seu discurso verbal, uma vez que tais gestos se relacionam de forma particular com os arranjos vocais específicos por ela mobilizados no discurso e, por isso, são entendidos como constitutivos do dizer. 


\section{Considerações finais}

Sendo assim, vemos nos arranjos vocais que caracterizam os recortes 1 e 2 a manifestação da subjetividade da criança na linguagem, já que ela mobiliza tais arranjos de forma a se relacionar com a língua e com a enunciação, condição para sua existência na linguagem. Ao se apropriar, portanto, dos arranjos vocais na constituição das modalidades da frase na relação viva e imediata com o outro, a criança assume sua condição de sujeito: ora os tons ascendentes marcam toda uma frase, ora marcam apenas um sintagma, ou apenas uma palavra; além disso, a criança, em alguns momentos, apropria-se do enunciado do outro, mas o enuncia com outra entonação, como ocorre nos três recortes que ilustram esse propósito, mobilizando um novo jogo de formas e sentidos, o que põe em evidência a singularidade enunciativa decorrente do aqui-agora em que a enunciação acontece.

Afirmamos, por fim, que há, nesses arranjos, a evidência da interpretância da língua em relação às funções inter-humanas do discurso, uma vez que, ao mobilizar os arranjos vocais específicos nas modalidades assertivas, interrogativas e imperativas da frase, a criança se move no simbólico da língua para agir sobre o outro e "transmitir-lhe um elemento do conhecimento, ou obter dele uma informação, ou darlhe uma ordem" (Benveniste 1964/2005:p. 139). Os arranjos assumem formas e sentidos dependentes da relação de emissão e de percepção vivenciada entre a criança e o outro da enunciação, refletindo "comportamentos fundamentais do homem falando e agindo pelo discurso sobre seu interlocutor" (Benveniste 1964/2005: p. 139), o que, certamente, representa uma experiência de aquisição da linguagem.

Recebido em outubro de 2016 Aprovado em março de 2017 E-mail: marlete@upf.br

\section{Referências bibliográficas}

Benveniste, Emile. (1958). Da subjetividade na linguagem. In: (1966). Problemas de Linguística Geral I. 5. ed. Campinas: Pontes, 2005. 
(1963). Vista d'olhos sobre o desenvolvimento da linguística. In: (1966). Problemas de Linguística Geral I. 5. ed. Campinas: Pontes, 2005.

. (1964). Os níveis de análise linguística. In: . (1966).

Problemas de Linguística Geral I. 5. ed. Campinas: Pontes, 2005. . (1966). A forma e o sentido na linguagem. In: (1974).

Problemas de Linguística Geral II. Campinas: Pontes, 1989. . (1968). Estrutura da língua e estrutura da sociedade. In:

(1974). Problemas de Linguística Geral II. Campinas: Pontes, 1989. . (1968). Estruturalismo e linguística. In.:

de Linguística Geral II. Campinas: Pontes, 1989. . (1969). Semiologia da língua. In: (1974). Problemas Linguística Geral II. Campinas: Pontes, 1989.
. (1970). O aparelho formal da enunciação. In: Linguística Geral II. Campinas: Pontes, 1989.
. (1970). O aparelho formal da enunciação. In: (1974). Problemas de . (1974).

Problemas de Linguística Geral II. Campinas: Pontes, 1989.

Dessons, Gérard. 2006. Émile Benveniste, l'invention du discours. Inpress.

Diedrich, Marlete Sandra. 2015. Aquisição da linguagem: o aspecto vocal da enunciação na experiência da criança na linguagem. Tese de doutorado. Universidade Federal do Rio Grande do Sul, Porto Alegre. Disponível em: http://hdl.handle.net/10183/130026.

Diedrich, Marlete Sandra \& Neumann, Daiane (Org.). 2012. Estudos da linguagem sob a perspectiva enunciativa. Passo Fundo: Méritos.

Flores, Valdir et alli. 2008. Enunciação e gramática. São Paulo: Contexto.

\& Surreaux, Luiza Milano. 2012. A voz e a enunciação. In.: Neumann, Daiane \& Diedrich, Marlete Sandra. (Org.). Estudos da linguagem sob a perspectiva enunciativa. Passo Fundo: Méritos.

FLORES, Valdir. 2013a. Sujeito da enunciação: singularidade que advém da sintaxe da enunciação. DELTA. Documentação de Estudos em Linguística Teórica e Aplicada (PUC SP. Impresso), v. 29, p. 95-120. . 2013b. Introdução à teoria enunciativa de Benveniste. São Paulo: Parábola.

JAKOBSON, Roman. 1968. Child language, aphasia and phonological universals. The Hague-Paris: Mouton.

SiLvA, Carmem Luci da Costa. 2009. A criança na linguagem: enunciação e aquisição. Campinas, SP: Pontes.

\& StumPF, Elisa Marchioro. 2012. O papel dos índices específicos e dos procedimentos acessórios na enunciação e na metaenunciação da criança. Desenredo, Revista do Programa de Pós-Graduação em Letras da Universidade de Passo Fundo, v. 8, n. 1, p. 115-143, jan./jun. 